\title{
Role of epidermal growth factor receptor tyrosine kinase inhibitors in the treatment of esophageal carcinoma and the suggested mechanisms of action (Review)
}

\author{
YAPING XU ${ }^{1}$, LIMING SHENG ${ }^{1}$ and WEIMIN MAO ${ }^{2}$ \\ Departments of ${ }^{1}$ Radiation Oncology and ${ }^{2}$ Thoracic Surgery, Zhejiang Cancer Hospital, \\ Hangzhou, Zhejiang 310022, P.R. China
}

Received June 26, 2012; Accepted October 4, 2012

DOI: $10.3892 / \mathrm{ol} .2012 .994$

\begin{abstract}
Cumulative evidence indicates that epidermal growth factor receptor (EGFR) is one of the most commonly altered genes in human cancer, via overexpression, amplification and mutation. Targeted inhibition of EGFR activity suppresses signal transduction pathways which control tumor cell growth, proliferation and resistance to apoptosis. Small molecule tyrosine kinase inhibitors (TKIs) are among the most common EGFR-targeting agents and have been used clinically to treat various malignancies. This review discusses the mechanism of action and clinical data that are relevant to the use of EGFR-TKIs in the treatment of esophageal carcinoma. The clinical and basic scientific experience of these agents thus far have implications for the future of therapeutic targeting of EGFR.
\end{abstract}

\section{Contents}

1. Introduction

2. EGFR and Barrett's esophagus

3. EGFR polymorphisms in esophageal carcinoma

4. EGFR mutation in esophageal carcinoma

5. Clinical studies

6. Gefitinib

7. Erlotinib

8. Conclusion

\section{Introduction}

Esophageal carcinoma is one of the most significant causes of cancer-related mortality among malignancies worldwide.

Correspondence to: Professor Weimin Mao, Department of Thoracic Surgery, Zhejiang Cancer Hospital, 38 Guangji Road, Hangzhou, Zhejiang 310022, P.R. China

E-mail: maowmzj1218@163.com

Key words: esophageal carcinoma, epidermal growth factor receptor, tyrosine kinase inhibitor, gefitinib, erlotinib
The incidence of esophageal carcinoma has quadrupled in the last three decades, with the 5-year survival rate less than $15 \%$. In the United States, the estimated incidence was 16,640 new cases and 14,500 mortalities in 2010 (1). Surgery is the main treatment option in localized, non-metastatic esophageal carcinoma $(2,3)$, while the benefits of chemotherapy or radiotherapy as adjuvant treatment are controversial $(4,5)$. The main site of treatment failure is locoregional recurrence. A minority of patients with locoregional failure may be salvaged with surgery or irradiation. With the improvements in locoregional control, distant metastasis is becoming more prevalent. The prognosis for patients with advanced esophageal carcinoma or recurrence is extremely poor, with a 5-6-month median overall survival (OS) time $(6,7)$. Although a number of regimens have been tested in randomized studies, there is uncertainty with regard to the choice of chemotherapy regimens. These observations have emphasized the need to develop new effective therapeutic approaches.

There is substantial evidence suggesting that epidermal growth factor receptor (EGFR) plays a key role in esophageal carcinoma. Increased EGFR expression may influence multiple aspects of tumor biology, including survival, proliferation of cells, motility, invasiveness and resistance to treatment (8-10). The success of active small molecule tyrosine kinase inhibitors (TKIs) targeted against EGFR in treating non-small cell lung cancer (NSCLC) has prompted research into their clinical benefits in numerous other solid tumors. This review discusses the role of EGFR-TKI in esophageal carcinoma, describes the characteristics of EGFR and discusses the treatments that target it and are currently available for esophageal carcinoma patients.

\section{EGFR and Barrett's esophagus}

Barrett's esophagus (BE) is the only known pre-malignant condition of esophageal adenocarcinoma and is associated with a $>40$-fold increased risk of developing cancer (11). However, the origin of BE cells and the mechanism by which the condition develops is poorly understood. EGFR plays a key role in the process of normal esophageal epithelial cell carcinogenesis. BE tissue may originate from esophageal squamous cells (12). Long-term exposure of squamous cells to bile and gastric 
acid causes the cells to differentiate to columnar cells. EGFR expression in esophageal preneoplastic tissues was found to be higher compared with that in normal epithelium (13) and caused uncontrolled proliferation by activating the autocrine growth pathway. Autonomous activation of EGFR amplifies tumorigenic processes, from metaplasia, low-grade dysplasia, high-grade dysplasia to adenocarcinoma (14). NF- $\mathrm{B}-\mathrm{CDX} 2$ axis activation (15) and COX-2 upregulation (8) have been observed in this process. EGFR-positive expression was observed in $60 \%$ of Barrett's-associated adenocarcinoma (16). EGFR overexpression enhanced tumor cell migration, mediated by the relocalization of p120 from the cytoplasm to the membrane, upregulation of MMP1 and increased interaction with E-cadherin (17). The rate of EGFR amplification in high-grade dysplasia/esophageal adenocarcinoma patients was $8-11 \%(18,19)$ and may serve as diagnostic marker.

Although EGFR expression and amplification have been found to be relatively common in Barrett's adenocarcinoma, the possibility of genetic heterogeneity should be considered. According to the study by Owonikoko et al (20), more EGFR gene amplification was detected in the tumor tissue center than in the periphery. In another study (15), identical EGFR amplification status was found in Barrett's adenocarcinoma primary tumors and corresponding lymph node metastases.

\section{EGFR polymorphisms in esophageal carcinoma}

Polymorphisms in EGFR have been identified to be functional and influence gene expression and promote EGFR activity and protein production. EGFR intron 1 has a highly polymorphic CA single sequence dinucleotide repeat region (CA-SSR1, typically consisting of 14-22 repeats) whose length has been found to inversely correlate with transcriptional efficiency (21). Short CA repeats were associated with increased EGFR transcript level and elevated tumor response to anti-EGFR therapy (22). In vitro, longer CA repeats were correlated with better clinical prognosis in lung cancer (23), pancreatic cancer (24) and head and neck cancer (25). The length of CA repeats also influence DNA bendability and the binding of repressor proteins (26,27). Another notable finding was the consistently identical length of CA repeats analyzed in matched tumor and normal tissues (28), indicating that this was a stable polymorphism that does not change over time and may be easily measured in normal and cancer tissues.

Lee et al performed a retrospective analysis of 148 Chinese patients who received cisplatin-based concurrent chemoradiotherapy (29). A long CA allele was defined as length of the CA repeats $\geq 20$, whereas alleles $<20$ CA repeats in length were classified as short alleles. The authors found that patients with the homozygous short allele of EGFR intron 1 had worse response and decreased survival time.

Another polymorphism EGFR G497A in EGFR, which attenuates the binding of EGF, has also been reported. The association between EGFR G497A and the risk of esophageal carcinoma was reported by Upadhyay et al in a study of an Asian population (30). No association of EGFR G497A genotype was observed (OR, 1.48; $\mathrm{P}=0.067)$, but the $\mathrm{EGFR}+61 \mathrm{~A} / \mathrm{A}$ genotype was significantly associated with risk of esophageal carcinoma $(\mathrm{OR}, 1.65 ; \mathrm{P}=0.025)$, particularly in males $(\mathrm{OR}$, 1.76; $\mathrm{P}=0.031)$. Similarly, another study has revealed a nega- tive correlation of EGFR G497A with clinical outcome in esophageal carcinoma patients treated with radiotherapy with or without chemotherapy (31).

\section{EGFR mutation in esophageal carcinoma}

In NSCLC, retrospective studies have consistently demonstrated clinical predictors of response to the EGFR-TKIs, including Asian ethnicity, female gender, adenocarcinoma histology and non-smoking history (32). Furthermore, patients who exhibit significant success with EGFR-TKI treatment have been reported to have genetic mutations in the EGFR gene. EGFR-TKI treatment sensitivity is highly dependent on EGFR mutations, especially in exons 18, 19, 20 and $21(33,34)$. Several studies have investigated the status of EGFR mutations in esophageal carcinoma.

Kwak et al sequenced exons 18 to 21 of EGFR from 21 cases of Barrett's esophagus, 5 cases of high-grade esophageal dysplasia and 17 cases of esophageal adenocarcinoma (35). This screening for mutations in exons 18 and 21 was performed as nearly all the mutations have been found in these regions. Somatic heterozygous EGFR mutations were identified in 2 of 21 esophageal cancers. One was the recurrent missense L858R and the other was an in-frame deletion, delE746-A750. Both were characterized as sensitizing EGFR mutations in NSCLC. However, the two patients with the EGFR mutation had not responded to EGFR-TKI (gefitinib) treatment. The study also reported EGFR mutations within this precancerous lesion. Three of 21 cases (14\%) of BE had an EGFR mutation. Two had the delE746-A750 sensitizing EGFR mutation, whereas the third had the T790M drug-resistance mutation.

Pühringer-Oppermann et al analyzed the sequences of exons 19 and 21 in 105 patients with esophageal adenocarcinoma (36). The majority of the samples were of the wild-type genotype and only one silent mutation in exon 19 was identified. Similarly, Sudo et al investigated the existence of EGFR mutations in esophageal cancer (37). They found that one of the 50 patients had an EGFR mutation in codon 719, resulting in an amino acid substitution from glycine to aspartic acid. In addition, the study analyzed EGFR mutation coding in 17 esophageal cancer cell lines. Three of the 17 cell lines had the same silent mutation at nucleotide 2607, a G-to-A substitution in exon 20. However, not all studies have confirmed this result. Janmaat et al investigated 36 patients with advanced esophageal cancer treated with gefitinib (38) and no EGFR mutation was observed.

Although there are limitations to the studies presented, including relatively small numbers of patients and a retrospective nature, the studies appear to suggest that EGFR mutations in esophageal carcinoma are rare but do exist. The association between EGFR mutation and esophageal carcinoma was reported by Kaneko et al, who analyzed the overexpression of EGFR protein and mutations in EGFR in esophageal squamous cell carcinoma patients who received chemoradiotherapy (39). The authors identified a silent mutation at codon 787 of exon 20 of the EGFR gene in 19 patients (33\%). The OS rate of patients with the EGFR mutation in exon 20 was lower than that of the patients without the mutation (OR, 2.347; 95\% CI, 1.183-4.656; $\mathrm{P}=0.015)$. The EGFR mutation in exon 20 was associated with decreased OS. 
Table I. Gefitinib in clinical trials for patients with esophageal carcinoma.

\begin{tabular}{|c|c|c|c|c|c|c|}
\hline First author (ref.) & $\begin{array}{l}\text { No. of } \\
\text { patients }\end{array}$ & $\begin{array}{l}\text { Line of } \\
\text { therapy }\end{array}$ & $\begin{array}{c}\text { Phase/treatment } \\
\text { model }\end{array}$ & $\begin{array}{c}\text { Grade } 3 / 4 \\
\text { toxicities }(\%)\end{array}$ & $\begin{array}{c}\text { Results } \\
\text { response }(\%)\end{array}$ & Survival \\
\hline Janmaat (38) & 36 & Second & $\begin{array}{l}\text { Phase II } \\
\text { gefitinib }\end{array}$ & $\begin{array}{l}\text { Diarrhea (8.3) } \\
\text { Rash (2.8) } \\
\text { Increased AST (2.8) } \\
\text { Increased ALT (2.8) } \\
\text { Vomiting (2.8) }\end{array}$ & $\begin{array}{l}\mathrm{PR}(2.8) \\
\mathrm{SD}(27.8)\end{array}$ & $\begin{array}{l}\text { MPFS, } 59 \text { days } \\
\text { MOS, } 164 \text { days }\end{array}$ \\
\hline Ferry (45) & 27 & Second & $\begin{array}{l}\text { Phase II } \\
\text { gefitinib }\end{array}$ & $\begin{array}{l}\text { Diarrhea (11.1) } \\
\text { Rash (18.5) }\end{array}$ & $\mathrm{PR}+\mathrm{SD}(37)$ & MPFS, 1.9 months \\
\hline Javle (46) & 6 & First & $\begin{array}{l}\text { Phase I/II } \\
\text { gefitinib + } \\
\text { oxaliplatin + RT }\end{array}$ & $\begin{array}{l}\text { Diarrhea } 1 / 6 \\
\text { Vomiting } 1 / 6 \\
\text { Fatigue } 1 / 6 \\
\text { Constipation } 2 / 6\end{array}$ & $\begin{array}{l}\text { CR } 1 / 6 \\
\text { PR } 1 / 6 \\
\text { SD } 1 / 6\end{array}$ & $\begin{array}{l}\text { MOS, } 10.8 \text { months } \\
\text { MPFS, } 8.4 \text { months }\end{array}$ \\
\hline Rodriguez (47) & 80 & First & $\begin{array}{l}\text { Phase II } \\
\text { gefitinib + } \\
\text { 5-FU/Cis + } \\
\text { RT + } \\
\text { Surgery }\end{array}$ & $\begin{array}{l}\text { Vomiting (1.3) } \\
\text { Mucositis (2.6) } \\
\text { Hematological } \\
\text { neutropenic fever (5) } \\
\text { ANC <1000/ } / 1(3.8)\end{array}$ & $\begin{array}{l}\text { pCR (7.5) } \\
\operatorname{pPR}(33.8)\end{array}$ & $\begin{array}{l}\text { 3-year OS, 42\% } \\
\text { 3-year LC, 76\% }\end{array}$ \\
\hline Sunpaweravong (48) & 37 & & $\begin{array}{l}\text { Phase II } \\
\text { gefitinib + } \\
\text { 5-FU/Cis } \pm \text { RT }\end{array}$ & $\begin{array}{l}\text { Hematological } \\
\text { neutropenia (19) } \\
\text { Leucopenia (19) } \\
\text { Anemia (16) }\end{array}$ & $\begin{array}{l}\text { Stage II-IVa: } \\
\text { CR (15) } \\
\text { PR (63) } \\
\text { SD (11) } \\
\text { Stage IVb: } \\
\text { PR (50) } \\
\text { SD (30) }\end{array}$ & NS \\
\hline
\end{tabular}

RT, radiotherapy; PR, partial response; SD, stable disease; CR, complete response; pCR, pathological complete response; pPR, pathological partial response; MPFS, median progression-free survival; MOS, median overall survival; OS, overall survival; LC, locoregional control; NS, not stated. AST, aspartate transanimase; ALT, alanine transanimase; ANC, absolute neutrophil count.

\section{Clinical studies}

Gefitinib and erlotinib are oral TKIs against EGFR. In 2005, a phase III clinical trial comparing gefitinib and placebo in advanced recurrent NSCLC failed to demonstrate increased survival (40), prompting the US FDA to restrict the use of gefinitib to patients who had previously benefited or continue to benefit from the treatment. Nevertheless, gefitinib is approved for use in a number of other countries, in certain cases as a first-line therapy. Erlotinib is FDA-approved for the treatment of patients with locally advanced or metastatic NSCLC, either following failure of at least one prior chemotherapy or, more recently, as maintenance therapy for patients whose disease has not progressed after four cycles of platinum-based chemotherapy. Erlotinib has also been approved for use with gemcitabine in the first-line treatment of pancreatic cancer, based on a phase III trial that demonstrated a small improvement in OS for the combination over gemcitabine alone, without significant improvement in the objective response rate (ORR) (41). EGFR-TKIs used as single-agent or combined with other treatments are being studied in esophageal carcinoma.

\section{Gefitinib}

In vitro, gefitinib exhibited a dose-dependant inhibition of cellular proliferation in esophageal carcinoma cells. Gefitinib inhibited EGF-induced autophosphorylation of EGFR and the downstream signaling pathways, Ras/Raf/MAPK and PI3K/Akt, and caused G1 arrest of cell cycle (42). Inhibition was also correlated with TRAIL-induced apoptosis enhancement via activation of caspase 3 and caspase 9 and inactivation of Bcl-xL (43). Taira et al reported that the combination of gefitinib and radiotherapy showed a synergistic effect and an additive effect in human esophageal carcinoma cell lines (44). Several studies have attempted to define the response rate and clinical outcomes of a treatment of using gefitinib in esophageal carcinoma patients. In 2006, Janmaat et al performed a phase II of 36 patients who had failed one line of prior chemotherapy and were treated with gefitinib $(500 \mathrm{mg} /$ day) (38). In this study, gefitinib showed a modest activity in second-line treatment of advanced esophageal carcinoma. Of the 36 enrolled patients, only one $(2.8 \%)$ achieved a partial response. The disease control rate was $30.6 \%$, which was less than previous results. The study also attempted to identify the 
Table II. Erlotinib in clinical trials for patients with esophageal carcinoma.

\begin{tabular}{|c|c|c|c|c|c|c|}
\hline First author (ref.) & $\begin{array}{l}\text { No. of } \\
\text { patients }\end{array}$ & $\begin{array}{l}\text { Line of } \\
\text { therapy }\end{array}$ & $\begin{array}{c}\text { Phase/treatment } \\
\text { model }\end{array}$ & $\begin{array}{c}\text { Grade } 3 / 4 \\
\text { toxicities }(\%)\end{array}$ & $\begin{array}{c}\text { Results } \\
\text { response }(\%)\end{array}$ & Survival \\
\hline Dobelbower (49) & 11 & First & $\begin{array}{l}\text { Phase I } \\
\text { erlotinib + } \\
\text { 5-FU/Cis + RT }\end{array}$ & $\begin{array}{l}\text { Rash 6/11 } \\
\text { Vomiting 1/11 } \\
\text { Dehydration 3/11 } \\
\text { Esophagitis } 2 / 11 \\
\text { Hematological: } \\
\text { WBC 4/11 } \\
\text { Hemoglobin 1/11 } \\
\text { Platelet 1/11 }\end{array}$ & NS & NS \\
\hline Ilson (50) & 30 & Second & $\begin{array}{l}\text { Phase II } \\
\text { erlotinib }\end{array}$ & Rash $10 \%$ & PR (6.7) & MOS, 10.3 months \\
\hline $\mathrm{Li}(51)$ & 24 & First & $\begin{array}{l}\text { Phase II } \\
\text { erlotinib + } \\
\text { Pac/Cis + RT }\end{array}$ & $\begin{array}{l}\text { Rash } 4.2 \% \\
\text { Esophagitis } 20.8 \% \\
\text { Hematological: } \\
\text { WBC } 16.7 \% \\
\text { Platelet } 8.3 \%\end{array}$ & $\begin{array}{l}\text { CR (45.8) } \\
\text { PR (45.8) }\end{array}$ & $\begin{array}{l}\text { 2-year OS, } 70.1 \% \\
\text { 2-year LC, } 87.5 \%\end{array}$ \\
\hline
\end{tabular}

RT, radiotherapy; PR, partial response; CR, complete response; MPFS, median progression-free survival; NS, not stated; MOS, median overall survival; OS, overall survival; LC, locoregional control; WBC, white blood cell count.

patients who were likely to benefit from gefitinib treatment. EGFR, PI3K and K-ras gene mutations were investigated. K-ras mutation was identified in two patients with progressive disease. Squamous cell carcinoma histology, female gender and EGFR protein overexpression may be predictors of response to gefitinib. Furthermore, diarrhea was a common adverse effect (58.3\%). During the treatment, four patients had a dose reduction for severe diarrhea and rash.

Similarly, in a phase II study, 27 patients with advanced inoperable adenocarcinoma of the esophagus underwent first-line target therapy with gefitinib (500 mg/day) until progression or unacceptable toxicity (45). Preliminary results revealed that three patients had a partial response and a $37 \%$ disease control rate with an acceptable toxicity profile. The study analyzed the change of gene expression of tumor tissue biopsy before and after the target treatment. The change in p-EGFR levels, although not statistically different, indicated that in a few patients there was suppression of p-EGFR expression following gefitinib therapy.

To date, one phase I/II study has assessed the safety and efficacy of gefitinib combined with chemoradiotherapy. In a previous trial (46), six patients with immunohistochemistry EGFR scores of 0 or 1+ were enrolled in the study. Preoperative radiotherapy was delivered in 1.8 Gy per fraction once daily over 28 days to a dose of 50.4 Gy. Intravenous oxaliplatin ( 85 or $100 \mathrm{mg} / \mathrm{m}^{2}$ ) was begun on the first day of radiation. Gefitinib (250 mg/day) was administered for 1 year. This combination treatment was well tolerated but showed limited efficacy. Three patients (50\%) experienced progressive disease during treatment. Median overall and disease-free survival times were 10.8 and 8.4 months, respectively. The lower dose of gefitinib (250 mg/day) and the lower
EGFR expression (5 patients with EGFR $1+$ and 1 patient $0+$ ) may have led to this lower clinical activity.

Although gefitinib had a modest response rate in the above studies, an OS benefit was exhibited in a phase II clinical trial (47). This was an open label phase II study of patients with locoregionally advanced esophageal (34 patients) or gastroesophageal junction (GEJ) carcinoma (46 patients). Gefitinib (250 $\mathrm{mg} / \mathrm{day}$ ) was administered with preoperative concurrent chemoradiotherapy (CCRT; RT, $30 \mathrm{~Gy}, 1.5 \mathrm{~Gy}$, BID; CT, cisplatin, $20 \mathrm{mg} / \mathrm{m}^{2} /$ day and fluorouracil, $1,000 \mathrm{mg} / \mathrm{m}^{2} /$ day) for 4 weeks and restarted with postoperative therapy for 2 years. The estimated 3 -year OS rate for patients receiving and not receiving gefitinib was 42 and $28 \%$, respectively $(\mathrm{P}=0.06)$. The estimated 3 -year OS rate for patients with and without diarrhea was 52 and $30 \%$, respectively $(\mathrm{P}=0.006)$.

Gefitinib has also been combined with 5-FU/cisplatin in a phase II evaluation of patients with stage II-IVb esophageal cancer, with preliminary data presented. Patients with stage IVb disease received gefitinib/5-FU/cisplatin while those with stage II-IVa disease also received concurrent radiation. Of the 25 evaluable patients with stage II-IVa disease, 4 underwent esophagectomy and 1 (4\% of patients enrolled or $25 \%$ of those who underwent surgery) was found to have a pathological complete response. Of 5 evaluable patients with stage IVb disease, the ORR was 50\% (48).

\section{Erlotinib}

Only three studies have evaluated the safety of erlotinib with or without chemoradiotherapy. Dobelbower et al (49) reported safety and tolerability of erlotinib delivered at 50, 100 or 
$150 \mathrm{mg} /$ day with concurrent 5-FU, cisplatin and thoracic radiation in a phase I study of esophageal carcinoma. A total of 11 patients with squamous cell carcinoma or adenocarcinoma of the esophagus were enrolled in this study. Two patients were discontinued from the study due to toxicities unrelated to erlotinib. There were no erlotinib dose reductions and no treatment delays. All patients experienced esophagitis during treatment (grade 1, 55\%; grade 2,32\%; grade 3,9\%; grade 4, $9 \%$ ). Radiation treatment was interrupted in two patients and resumed after 3 days when esophagitis improved. The other major toxicities were grade 1 or 2 diarrhea, skin rash, nausea and dehydration. The study by Ilson et al (50) evaluated the feasibility and efficacy of erlotinib in patients with previously treated esophageal cancer. A total of 30 patients with esophageal and GEJ carcinoma received $150 \mathrm{mg}$ erlotinib daily. Patients continued therapy until disease progression or unacceptable toxicity. EGFR overexpression was observed in 24 patients $(80 \%)$. The response rate was $6.7 \%$, with response duration 5.5-7.0 months. Of the 30 patients, $13 \%$ had grade 2 diarrhea. Grade 3 hematological toxicity was observed in $10 \%$ of patients and $67 \%$ of patients experienced grade 3 skin rash. The authors concluded that erlotinib had limited activity in patients with esophageal cancer, requiring further evaluation in squamous cell carcinoma. More recently, another phase II study (51) investigated the feasibility and efficacy of CCRT in combination with erlotinib for locally advanced esophageal carcinoma. A total of 24 patients with locally advanced esophageal carcinoma were treated with concurrent chemotherapy (paclitaxel $135 \mathrm{mg} / \mathrm{m}^{2}$ days 1 and 29; cisplatin $20 \mathrm{mg} / \mathrm{m}^{2}$ days 1-3 and 29-31) and chest radiation (60 Gy, 2.0 Gy/day). All patients were treated with $150 \mathrm{mg}$ erlotinib daily. Partial response was observed in 11 patients $(45.8 \%)$ and complete response in 11 patients $(45.8 \%)$, as confirmed by chest CT scan and barium swallow. The 2-year OS, local-regional control and relapse-free survival rates were $70.1 \%$ (95\% CI, 50.4-90), $87.5 \%$ (95\% CI, 73.5-100) and 57.4\% (95\% CI, 36.3-78.7), respectively. The incidence of acute grade esophagitis toxicities was $20.8 \%$. Hematological toxicity and skin rash were also significant but manageable.

Overall, gefitinib and erlotinib have little single-agent activity in the first- or second-line setting in esophageal carcinoma. Although no specific conclusions may be drawn, it may be that patients who are more likely to respond have tumors that have squamous cell carcinoma histology and EGFR overexpression. The toxicities in all these trials were similar. In general, therapy was well tolerated, with diarrhea and skin rash being the major toxicities. These occurred in $30-70 \%$ and $47-86 \%$ of patients, respectively, but were mostly grade $1 / 2(52)$.

\section{Conclusion}

Medical development in cancer therapeutics has been transformed by our increasing understanding of the cellular mechanisms of carcinogenesis. Multidisciplinary studies, including use of the novel targeted therapies described in this review as single agents or in combination with chemotherapy or chemoradiotherapy, to identify patient- and tumor-specific markers predictive for response and/or toxicity remain urgently needed for esophageal carcinoma.

\section{Acknowledgements}

This study was sponsored by the China Wu Jieping Medical Foundation-EGFR targeted therapy basic research projects (08-ZH-006 to Yaping $\mathrm{Xu}$ ). This manuscript was edited and proofread by Paul Stanton prior to submission.

\section{References}

1. Jemal A, Siegel R, Xu J and Ward E: Cancer statistics, 2010. CA Cancer J Clin 60: 277-300, 2010.

2. McKenzie S, Mailey B, Artinyan A, Metchikian M, Shibata S, Kernstine K and Kim J: Improved outcomes in the management of esophageal cancer with the addition of surgical resection to chemoradiation therapy. Ann Surg Oncol 18: 551-558, 2011.

3. Mariette C, Taillier G, Van Seuningen I and Triboulet JP: Factors affecting postoperative course and survival after en bloc resection for esophageal carcinoma. Ann Thorac Surg 78: 1177-1183, 2004.

4. Ruol A, Rizzetto C, Castoro C, et al: Interval between neoadjuvant chemoradiotherapy and surgery for squamous cell carcinoma of the thoracic esophagus: does delayed surgery have an impact on outcome? Ann Surg 252: 788-796, 2010.

5. Hironaka S, Ohtsu A, Boku N, et al: Nonrandomized comparison between definitive chemoradiotherapy and radical surgery in patients with T (2-3) N (any) M (0) squamous cell carcinoma of the esophagus. Int J Radiat Oncol Biol Phys 57: 425-433, 2003.

6. Park BB, Im YH, Hwang IG, et al: Salvage chemotherapy with mitomycin C, ifosfamide, and cisplatin (MIC) for previously treated metastatic or recurrent esophageal squamous cell carcinoma. Invest New Drugs 26: 387-392, 2008.

7. Jin J, Xu X, Wang F, et al: Second-line combination chemotherapy with docetaxel and nedaplatin for Cisplatin-pretreated refractory metastatic/recurrent esophageal squamous cell carcinoma. J Thorac Oncol 4: 1017-1021, 2009.

8. Li Y, Wo JM, Ray MB, Jones W, Su RR, Ellis S and Martin RC: Cyclooxygenase-2 and epithelial growth factor receptor up-regulation during progression of Barrett's esophagus to adenocarcinoma. World J Gastroenterol 12: 928-934, 2006.

9. Gibault L, Metges JP, Conan-Charlet V, et al: Diffuse EGFR staining is associated with reduced overall survival in locally advanced oesophageal squamous cell cancer. Br J Cancer 93: 107-115, 2005.

10. Hoshino M, Fukui H, Ono Y, et al: Nuclear expression of phosphorylated EGFR is associated with poor prognosis of patients with esophageal squamous cell carcinoma. Pathobiology 74: 15-21, 2007.

11. Shaheen NJ, Crosby MA, Bozymski EM and Sandler RS: Is there publication bias in the reporting of cancer risk in Barrett's esophagus? Gastroenterology 119: 333-338, 2000.

12. Goldman A, Chen HD, Roesly HB, et al: Characterization of squamous esophageal cells resistant to bile acids at acidic $\mathrm{pH}$ : implication for Barrett's esophagus pathogenesis. Am J Physiol Gastrointest Liver Physiol 300: G292-G302, 2011.

13. Wang QS, Sabourin CL, Bijur GN, Robertson FM and Stoner GD: Alterations in transforming growth factor-alpha and epidermal growth factor receptor expression during rat esophageal tumorigenesis. Mol Carcinog 15: 144-153, 1996.

14. Gong L, Debruyne PR, Witek M, et al: Bile acids initiate lineage-addicted gastroesophageal tumorigenesis by suppressing the EGF receptor-AKT axis. Clin Transl Sci 2: 286-293, 2009.

15. Marx AH, Zielinski M, Kowitz CM, et al: Homogeneous EGFR amplification defines a subset of aggressive Barrett's adenocarcinomas with poor prognosis. Histopathology 57: 418-426, 2010.

16. Yacoub L, Goldman H and Odze RD: Transforming growth factor-alpha, epidermal growth factor receptor, and MiB-1 expression in Barrett's-associated neoplasia: correlation with prognosis. Mod Pathol 10: 105-112, 1997.

17. Andl CD, Mizushima T, Nakagawa H, et al: Epidermal growth factor receptor mediates increased cell proliferation, migration, and aggregation in esophageal keratinocytes in vitro and in vivo. J Biol Chem 278: 1824-1830, 2003.

18. Miller CT, Moy JR, Lin L, et al: Gene amplification in esophageal adenocarcinomas and Barrett's with high-grade dysplasia. Clin Cancer Res 9: 4819-4825, 2003. 
19. Rygiel AM,MilanoF,Ten KateFJ,etal: Gains and amplifications of c-myc, EGFR, and 20.q13 loci in the no dysplasia-dysplasia-adenocarcinoma sequence of Barrett's esophagus. Cancer Epidemiol Biomarkers Prev 17: 1380-1385, 2008.

20. Owonikoko T, Rees M, Gabbert HE and Sarbia M: Intratumoral genetic heterogeneity in Barrett adenocarcinoma. Am J Clin Pathol 117: 558-566, 2002.

21. Gebhardt F, Zänker KS and Brandt B: Modulation of epidermal growth factor receptor gene transcription by a polymorphic dinucleotide repeat in intron 1. J Biol Chem 274: 13176-13180, 1999.

22. Buerger $\mathrm{H}$, Gebhardt F, Schmidt $\mathrm{H}$, et al: Length and loss of heterozygosity of an intron 1 polymorphic sequence of egfr is related to cytogenetic alterations and epithelial growth factor receptor expression. Cancer Res 60: 854-857, 2000.

23. Tiseo M, Capelletti M, De Palma G, et al: Epidermal growth factor receptor intron-1 polymorphism predicts gefitinib outcome in advanced non-small cell lung cancer. J Thorac Oncol 3 : 1104-1111, 2008.

24. Tzeng CW, Frolov A, Frolova N, et al: Pancreatic cancer epidermal growth factor receptor (EGFR) intron 1 polymorphism influences postoperative patient survival and in vitro erlotinib response. Ann Surg Oncol 14: 2150-2158, 2007.

25. Etienne-Grimaldi MC, Pereira S, Magné N, et al: Analysis of the dinucleotide repeat polymorphism in the epidermal growth factor receptor (EGFR) gene in head and neck cancer patients. Ann Oncol 16: 934-941, 2005.

26. Brandt B, Meyer-Staeckling S, Schmidt H, Agelopoulos K and Buerger $\mathrm{H}$ : Mechanisms of egfr gene transcription modulation: relationship to cancer risk and therapy response. Clin Cancer Res 12: 7252-7260, 2006.

27. Gebhardt F, Bürger $\mathrm{H}$ and Brandt B: Modulation of EGFR gene transcription by a polymorphic repetitive sequence - a link between genetics and epigenetics. Int J Biol Markers 15: 105-110, 2000.

28. Amador ML, Oppenheimer D, Perea S, et al: An epidermal growth factor receptor intron 1 polymorphism mediates response to epidermal growth factor receptor inhibitors. Cancer Res 64 9139-9143, 2004.

29. Lee JM, Yang SY, Yang PW, et al: Polymorphism in epidermal growth factor receptor intron 1 predicts prognosis of patients with esophageal cancer after chemoradiation and surgery. Ann Surg Oncol 18: 2066-2073, 2011.

30. Upadhyay R, Jain M, Kumar S, Ghoshal UC and Mittal B Interaction of EGFR 497Arg $>$ Lys with EGF $+61 \mathrm{~A}>\mathrm{G}$ polymorphism: modulation of risk in esophageal cancer. Oncol Res 17: 167-174, 2008

31. Jain M, Kumar S, Upadhyay R, Lal P, Tiwari A, Ghoshal UC and Mittal B: Influence of apoptosis (BCL2, FAS), cell cycle (CCND1) and growth factor (EGF, EGFR) genetic polymorphisms on survival outcome: an exploratory study in squamous cell esophageal cancer. Cancer Biol Ther 6: 1553-1558, 2007.

32. Miller VA, Kris MG, Shah N, et al: Bronchioloalveolar pathologic subtype and smoking history predict sensitivity to gefitinib in advanced non-small-cell lung cancer. J Clin Oncol 22: 1103-1109, 2004.

33. Paez JG, Jänne PA, Lee JC, et al: EGFR mutations in lung cancer: correlation with clinical response to gefitinib therapy. Science 304: 1497-1500, 2004

34. Lynch TJ, Bell DW, Sordella R, et al: Activating mutations in the epidermal growth factor receptor underlying responsiveness of non-small-cell lung cancer to gefitinib. N Engl J Med 350: 2129-2139, 2004

35. Kwak EL, Jankowski J, Thayer SP, et al: Epidermal growth factor receptor kinase domain mutations in esophageal and pancreatic adenocarcinomas. Clin Cancer Res 12: 4283-4287, 2006
36. Pühringer-Oppermann FA, Stein HJ and Sarbia M: Lack of EGFR gene mutations in exons 19 and 21 in esophageal (Barrett's) adenocarcinomas. Dis Esophagus 20: 9-11, 2007.

37. Sudo T, Mimori K, Nagahara H, et al: Identification of EGFR mutations in esophageal cancer. Eur J Surg Oncol 33: 44-48, 2007.

38. Janmaat ML, Gallegos-Ruiz MI, Rodriguez JA, et al: Predictive factors for outcome in a phase II study of gefitinib in second-line treatment of advanced esophageal cancer patients. J Clin Oncol 24: 1612-1619, 2006.

39. Kaneko K, Kumekawa Y, Makino R, et al: EGFR gene alterations as a prognostic biomarker in advanced esophageal squamous cell carcinoma. Front Biosci 15: 65-72, 2010.

40. Thatcher N, Chang A, Parikh P, et al: Gefitinib plus best supportive care in previously treated patients with refractory advanced non-small-cell lung cancer: results from a randomised, placebo-controlled, multicentre study (Iressa Survival Evaluation in Lung Cancer). Lancet 366: 1527-1537, 2005.

41. Moore MJ, Goldstein D, Hamm J, et al: Erlotinib plus gemcitabine compared with gemcitabine alone in patients with advanced pancreatic cancer: a phase III trial of the national cancer institute of Canada clinical trials group. J Clin Oncol 25: 1960-1966, 2007.

42. Hara F, Aoe M, Doihara H, et al: Antitumor effect of gefitinib ('Iressa') on esophageal squamous cell carcinoma cell lines in vitro and in vivo. Cancer Lett 226: 37-47, 2005.

43. Teraishi F, Kagawa S, Watanabe T, et al: ZD1839 (Gefitinib, 'Iressa'), an epidermal growth factor receptor-tyrosine kinase inhibitor, enhances the anti-cancer effects of TRAIL in human esophageal squamous cell carcinoma. FEBS Lett 579: 4069-4075, 2005.

44. Taira N, Doihara H, Oota T, et al: Gefitinib, an epidermal growth factor receptor blockade agent, shows additional or synergistic effects on the radiosensitivity of esophageal cancer cells in vitro. Acta Med Okayama 60: 25-34, 2006.

45. Ferry DR, Anderson M, Beddard K, et al: A phase II study of gefitinib monotherapy in advanced esophageal adenocarcinoma: evidence of gene expression, cellular, and clinical response. Clin Cancer Res 13: 5869-5875, 2007.

46. Javle M, Pande A, Iyer R, et al: Pilot study of gefitinib, oxaliplatin, and radiotherapy for esophageal adenocarcinoma: tissue effect predicts clinical response. Am J Clin Oncol 31: 329-334, 2008.

47. Rodriguez CP, Adelstein DJ, Rice TW, et al: A phase II study of perioperative concurrent chemotherapy, gefitinib, and hyperfractionated radiation followed by maintenance gefitinib in locoregionally advanced esophagus and gastroesophageal junction cancer. J Thorac Oncol 5: 229-235, 2010.

48. Sunpaweravong P, Sunpaweravong S, Sangthawan D, PuttawibulP and Mitarnun W: Combination of gefitinib, cisplatin and 5-FU chemotherapy, and radiation therapy (RT) in newly-diagnosed patients with esophageal carcinoma. J Clin Oncol 25: 4605, 2007.

49. Dobelbower MC, Russo SM, Raisch KP, et al: Epidermal growth factor receptor tyrosine kinase inhibitor, erlotinib, and concurrent 5-fluorouracil, cisplatin and radiotherapy for patients with esophageal cancer: a phase I study. Anticancer Drugs 17: 95-102, 2006

50. Ilson DH, Kelsen D, Shah M, et al: A phase 2 trial of erlotinib in patients with previously treated squamous cell and adenocarcinoma of the esophagus. Cancer 117: 1409-1414, 2011.

51. Li G, Hu W, Wang J, et al: Phase II study of concurrent chemoradiation in combination with erlotinib for locally advanced esophageal carcinoma. Int J Radiat Oncol Biol Phys 78: $1407-1412,2010$.

52. Ku GY and Ilson DH: Esophagogastric cancer: targeted agents. Cancer Treat Rev 36: 235-248, 2010. 